\title{
Overexpression of the duffy antigen receptor for chemokines (DARC) by NSCLC tumor cells results in increased tumor necrosis Christina L Addison ${ }^{1}$, John A Belperio ${ }^{2}$, Marie D Burdick ${ }^{2}$ and Robert M Strieter*2
}

Address: ${ }^{1}$ Centre for Cancer Therapeutics, Ottawa Regional Cancer Centre, 503 Smyth Road, Ottawa, Ontario, K1H 1C4 Canada and ${ }^{2}$ Departments of Medicine, Pathology, and Pediatrics, Division of Pulmonary and Critical Care Medicine, UCLA School of Medicine, Los Angeles CA, 900241922 USA

Email: Christina L Addison - Christina.Addison@orcc.on.ca; John A Belperio - jbelpario@mednet.ucla.edu; Marie D Burdick - mburdick@mednet.ucla.edu; Robert M Strieter* - rstrieter@mednet.ucla.edu

* Corresponding author

Published: 23 June 2004

BMC Cancer 2004, 4:28 doi:10.1/86/147|-2407-4-28
Received: 22 March 2004

Accepted: 23 June 2004

This article is available from: http://www.biomedcentral.com/I47I-2407/4/28

(c) 2004 Addison et al; licensee BioMed Central Ltd. This is an Open Access article: verbatim copying and redistribution of this article are permitted in all media for any purpose, provided this notice is preserved along with the article's original URL.

\begin{abstract}
Background: The Duffy antigen receptor for chemokines (DARC) is known to be a promiscuous chemokine receptor that binds a variety of CXC and CC chemokines in the absence of any detectable signal transduction events. Within the CXC group of chemokines, DARC binds the angiogenic CXC chemokines including IL-8 (CXCL8), GRO $\alpha$ (CXCLI) and ENA-78 (CXCL5), all of which have previously been shown to be important in non-small cell lung carcinoma (NSCLC) tumor growth. We hypothesized that overexpression of DARC by a NSCLC tumor cell line would result in the binding of the angiogenic ELR+ CXC chemokines by the tumor cells themselves, and thus interfere with the stimulation of endothelial cells and induction of angiogenesis by the tumor cell-derived angiogenic chemokines.
\end{abstract}

Results: NSCLC tumor cells that constitutively expressed DARC were generated and their growth characteristics were compared to control transfected cells in vitro and in vivo in SCID animals. We found that tumors derived from DARC-expressing cells were significantly larger in size than tumors derived from control-transfected cells. However, upon histological examination we found that DARC-expressing tumors had significantly more necrosis and decreased tumor cellularity, as compared to control tumors. Expression of DARC by NSCLC cells was also associated with a decrease in tumor-associated vasculature and a reduction in metastatic potential.

Conclusions: The expression of DARC in the context of NSCLC tumors may act as a chemokine decoy receptor and interferes with normal tumor growth and chemokine-induced tumor neovascularization.

\section{Background}

DARC was originally identified as a blood group antigen, and later as a coreceptor for malaria [1-3]. More recently, it was demonstrated that DARC binds a variety of CXC and CC chemokines [4-7]. In particular, DARC binds to the CC chemokines monocyte chemotatic protein-1 (MCP-1; CCL2) and regulated upon activation normal T expressed and secreted (RANTES; CCL5), and the CXC chemokines interleukin-8 (IL-8, CXCL8), growth related gene alpha (GRO- $\alpha$, CXCL1), and neutrophil activating 
peptide-2 (NAP-2, CXCL7). Expression of DARC in vivo is not limited to the red blood cell, and DARC expression has been detected in endothelial cells of the kidney, spleen and brain and in large vessel and post-capillary venules [1,2]. It has also been detected in epithelial cells lining the ducts of the kidney, in pulmonary alveoli [8], and in a subset of neurons [9]. Interestingly, DARC is also expressed in endothelial cell types in individuals who lack expression of DARC (Duffy antigen negative) on their red blood cells $[6,10]$. Therefore, the expression of DARC by cells other than red blood cells suggests that its presence on these cells may be important in modifying the biological behavior of specific chemokines.

Similar to other receptors identified to date that are known to bind chemokines, DARC is a seven-transmembrane receptor, however, unlike other chemokine receptors, ligand binding by DARC does not induce G-protein coupled signal transduction nor a $\mathrm{Ca}^{2+}$-flux [11]. Amino acid alignment with other seven-transmembrane G-protein coupled receptors indicates that DARC lacks a highly conserved DRY motif in the second intracellular loop of the protein that is known to be associated with G-protein signaling [12]. Despite the lack of evidence for DARC signal transduction, it has been shown in DARC-transfected cells that DARC is internalized following ligand binding [10]. These results have led to the hypothesis that expression of DARC on the surface of red blood cells, endothelial, neuronal cells, and epithelial cells may act as a sponge and provide a mechanism by which inflammatory chemokines may be removed from circulation as well as their concentration modified in the local environment.

The members of the CXC chemokine family that bind DARC are also known to induce angiogenic responses in a variety of assays. The ELR+ CXC chemokines IL-8, GRO$\alpha$ and epithelial neutrophil activating protein 78 (ENA78 , CXCL5) have all been shown to be important mediators of tumor-derived angiogenesis in vivo [13-19]. Neutralization of ELR+ CXC chemokines in SCID mouse models of human non-small cell lung cancer (NSCLC), as well as human prostate cancer has demonstrated that these molecules significantly contribute to tumor-associated neovascularization, tumor progression and metastasis [17-19]. Interestingly, the angiostatic members of the CXC chemokine family, namely the ELR- CXC chemokines interferon inducible protein-10 (IP-10, CXCL10) and monokine induced by $\gamma$-interferon (MIG, CXCL9) do not bind to DARC [7]. Thus DARC demonstrates a disparate activity in its ability to bind to angiogenic versus angiostatic chemokines, and thus might contribute to the net angiogenic activity within the local tumor microenvironment.
We hypothesized that over-expression of DARC in a tumor could lead to sequestering of angiogenic chemokines from the local vascular environment and thus inhibit tumor-associated neovascularization and tumor progression. To test this hypothesis, we chose a model of human NSCLC, A549 cells, whose growth and metastatic potential in vivo has been previously shown to be dependent on the production of angiogenic ELR + CXC chemokines by the tumor cells $[17,18]$. We predicted that expression of DARC by the A549 tumor cells would lead to the binding of angiogenic chemokines by the tumor cells themselves and would result in the sequestering of angiogenic factors away from the tumor-associated endothelial cells. When A549 cells were transfected to stably over-express human DARC, we found that over-expression of DARC by two independently generated tumor cell clones resulted in increased tumor size compared to control transfected cells. Although tumor size was increased, the overexpression of DARC within the tumor was associated with marked tumor necrosis, reduced tumor cellularity, reduced vascularity, and impaired metastatic potential, as compared to the control tumors. These results indicate that DARC expression within the tumor microenvironment alters the characteristics of tumor growth and interferes with tumor-derived neovascularization, tumor cellularity and metastatic potential.

\section{Results \\ Generation and characterization of DARC-A549 cells}

The cDNA for human DARC was generated by RT-PCR and cloned into the pTARGET plasmid. The resulting construct was used to transfect human A549 cells, and following G418 selection, individual cell clones were isolated and expanded. Two clones were selected for further analysis, DARC1A6 and DARC2F5. Expression of DARC in these clones was confirmed by both northern blot detection of mRNA and by detection of surface expression of DARC protein by FACS analysis. We detected DARC-specific message in both the DARC1A6 and DARC2F5 clones, however no corresponding band was detected in the pTARGET empty vector control transfected A549 cell clone by northern blot analysis (Fig. 1). The absence of DARC message in control cells was not due to unequal RNA loading as the 28S and 18 S message was similar in all three RNA samples (Fig. 1). We also confirmed the expression of DARC protein in the transfected cell lines following FACS analysis using the Fy6 monoclonal antibody specific to human DARC (Fig. 2A). There was an increase in the number of cells staining positive for DARC in both DARC1A6 and DARC2F5 cells as compared to control transfected cells. Although it would appear that only a percentage of transfected cells express DARC at the surface of the cell, this is in agreement with the fact that these cells also make IL-8 and ENA-78, therefore it is likely that DARC is binding these chemokines in the endoplasmic 


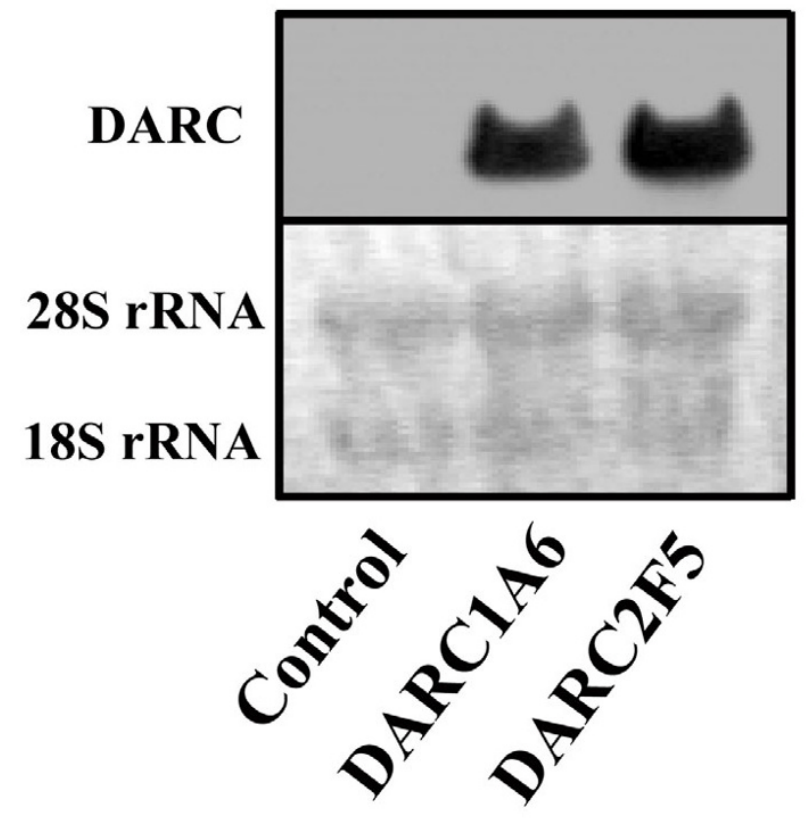

Figure I

Northern Blot Analysis of DARC-A549 transfectants. $10 \mu \mathrm{g}$ of total RNA from each cell clone was subjected to northern blot transfer. Expression levels of mRNA for each probe was densitometrically analyzed and compared to the signal obtained for the 28S rRNA. We observed DARC expression only in the A549 cells that had been transfected with a DARC-containing plasmid while the PTARGET control plasmid transfectanted appeared negative for DARC expression.

reticulum or the Golgi apparatus prior to their secretion thus preventing a proportion of DARC being expressed in these cells from being presented on the surface of tumor cells and thus subsequently detected by FACS. The presence of functional DARC protein on the surface of the transfected cells was also supported by the demonstration of increased binding of biotinylated IL-8 in DARC1A6 and DARC2F5 cells as compared to control cells (Fig. 2B). Taken together, these results indicate that DARC is constitutively expressed at the message level and can be found expressed at the cell surface in the DARC-transfected A549 cell clones to some degree. Furthermore, these results demonstrate that the DARC-expressing A549 cell lines have an increased capacity to bind an angiogenic ELR+ CXC chemokine as compared to control A549 cells, and
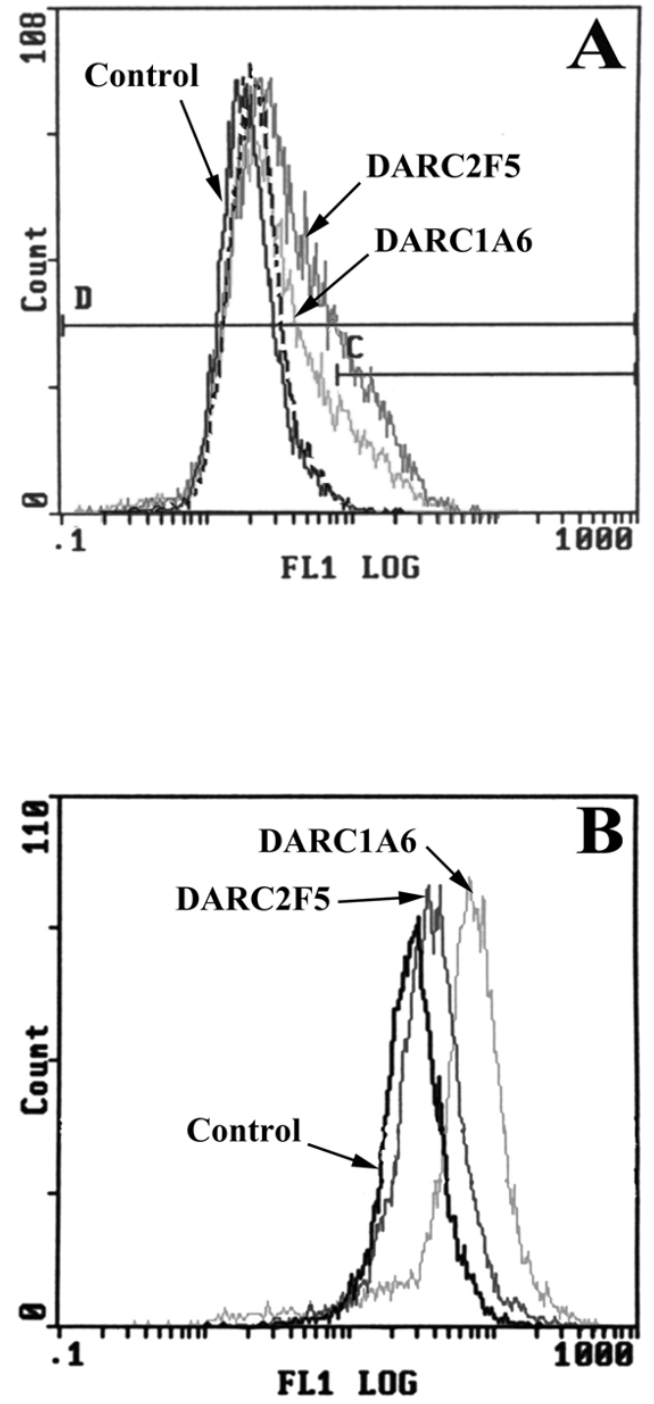

Figure 2

DARC-A549 transfectants have increased expression of DARC protein and an increased ability to bind IL-8. A) The expression of DARC by transfected cells was determined by FACS analysis using the DARC-specific antibody Fy6. We saw no increase in the fluorescent intensity of the Control cell line following addition of the Fy6 antibody (solid black line) as compared to IgG isotype control (dotted black line). For both DARCIA6 (light gray line) and DARC2F5 (dark gray line) we observed an increase in the fluorescent intensity following addition of Fy6 antibody suggesting the expression of the protein on the surface of DARC-transfected cells. B) We observed an increase in IL-8 binding in both DARCIA6 (light gray line) and DARC2F5 (dark gray line) as compared to the Control transfected A549 cell line (black line), indicating increased and functional ligand binding of IL-8 in DARC-expressing cell lines. 
thus in vivo may act as a "sink" to bind soluble angiogenic chemokines and inhibit tumor-associated angiogenesis.

We also compared the ability of DARC transfected cells to produce the angiogenic ELR+ CXC chemokines IL-8, ENA78 , GRO- $\alpha$ and GRO- $\gamma$ (CXCL3) as compared to control transfected tumor cells. Supernatants were removed from the cells following a $72 \mathrm{hr}$ incubation period and the amount of each chemokine present in conditioned supernatants was determined by specific ELISA for each chemokine. As compared to control transfected A549 cells we saw a decrease in the amount of both IL- 8 and ENA-78 present in the conditioned supernatants of the DARCexpressing cell lines (Fig. 3A \&3B). The differences in the amount of ELR+ CXC chemokine expression between the various cell clones was not likely a result of differences in transcription of each message, as both DARC-expressing A549 cell clones were found to have similar message levels for IL-8 and ENA-78 as compared to control A549 cells following northern blot analysis for specific message (data not shown). Thus the apparent discrepancy in the quantities of chemokines expressed by DARC-A549 cell clones might be due to differences in the amount of chemokines bound in an autocrine and paracrine manner by DARC expressed within cells as a result of binding to DARC in the golgi or endoplasmic reticulum in DARC expressing cells or the binding of secreted ELR+ CXC chemokines on the surface of the DARC-transfected cells. In addition to the DARC-binding chemokines we also examined the amounts of two chemokines being secreted that do not bind to DARC, namely IP-10 and MIG. We observed low but equivalent levels of MIG being secreted by DARC and control transfected A549 cells $(0.18 \pm 0.07$ $\mathrm{ng} / \mathrm{ml}$ for DARC1A6, $0.17 \pm 0.13 \mathrm{ng} / \mathrm{ml}$ for DARC2F5 and $0.165 \pm 0.11 \mathrm{ng} / \mathrm{ml}$ for control transfected A549 cells) and could not detect any IP-10 being secreted by any of the cell lines tested. The fact that DARC-transfected cell lines made equivalent amounts of the non-angiogenic chemokine MIG, which does not bind DARC, and that the DARCtransfected cell clones had reduced amounts of the angiogenic chemokines IL-8 and ENA-78, suggests that the reduction in chemokines being secreted into the medium was specific to those ELR+ CXC chemokines that bind DARC.

\section{Growth of DARC-A549 cells in SCID mice}

Tumor growth in vivo is influenced by the dynamic equilibrium of tumor cell growth and the ability to support this growth through the induction of neovascularization. Angiogenic activity is a result of the balance between angiogenic vs. angiostatic factors produced and available to endothelial cells in the local environment. In particular, NSCLC growth has been shown to be dependent on the ELR+ CXC chemokines and their potential interactions with DARC, CXCR2 and glycosaminoglycans (GAGs). We decided to determine the growth kinetics of the DARCexpressing tumor cells in vivo in a SCID mouse model. Since the DARC-expressing clones appeared to have slight differences in the secreted levels of the ELR+ CXC chemokines as compared to the control cells, we predicted that the DARC-expressing tumor cells would be impaired in their ability to form tumors in vivo as a result of impaired ability of ELR+ CXC chemokines to be secreted and form the appropriate chemotactic gradients necessary to induce tumor-associated angiogenesis. As can be seen in Fig. 4, both DARC-expressing A549 cell clones readily formed tumors in vivo, and in fact these tumors were measurably larger than those formed by control transfected A549 cells. We observed a 2.6-fold and a 3.2-fold increase in tumor size of DARC2F5 $\left(3737 \pm 423 \mathrm{~mm}^{3}\right)$ and DARC1A6 $\left(4523 \pm 532 \mathrm{~mm}^{3}\right)$ compared to control cell tumors $\left(1424 \pm 347 \mathrm{~mm}^{3}\right)$ respectively (Fig. 4). Following the 7-week duration of the experiment, animals were euthanized and portions of the tumors were processed for histological examination, examination of cell subtypes by FACS analysis of single cell suspensions, and examination of the levels of tumor-associated chemokine proteins by ELISA of tumor homogenates. We obtained $6 \mathrm{~mm}$ biopsy punch samples from each tumor and generated single cell suspensions that were subjected to FACS analysis for human CD49b, a marker for A549 cells, and for mouse CD31, a marker for murine endothelial cells. We observed a reduction in the percentage of CD49b positive cells in both DARC transfected cell line-derived tumors as compared to the control cell-derived tumors (Fig. 5). In addition, this observation was confirmed at both 3 and 4 weeks of tumor growth. Thus DARC-expressing tumors appeared to have fewer tumor cells per unit volume of tumor as compared to control tumors. This observation was also confirmed following histological examination of paraffin embedded tumor tissue. We found that although DARC-A549 cells generated tumors that were measurably larger than controls, these tumors had a reduction in the number of tumor cells and an increased degree of necrosis following examination of hemotoxylin and eosin stained sections (Fig. 6). In an attempt to compare the degree of tumor necrosis, we quantitated the percent necrosis from histological sections of each tumor using morphometric analysis and calculated the relative necrotic volume of each tumor as described in materials and methods. Tumors derived from both the DARC1A6 and DARC2F5 cell clones had statistically significant increases in necrotic volume as compared to control tumors (Fig. 7, p $\leq$ 0.0007). These data indicate that DARC-A549 derived tumors were more necrotic and contained fewer viable A549 tumor cells than did control tumors.

To confirm that DARC-A549 tumors contained fewer viable cells than tumors derived from the control A549 cells, we determined the percentage of apoptotic tumor cells 

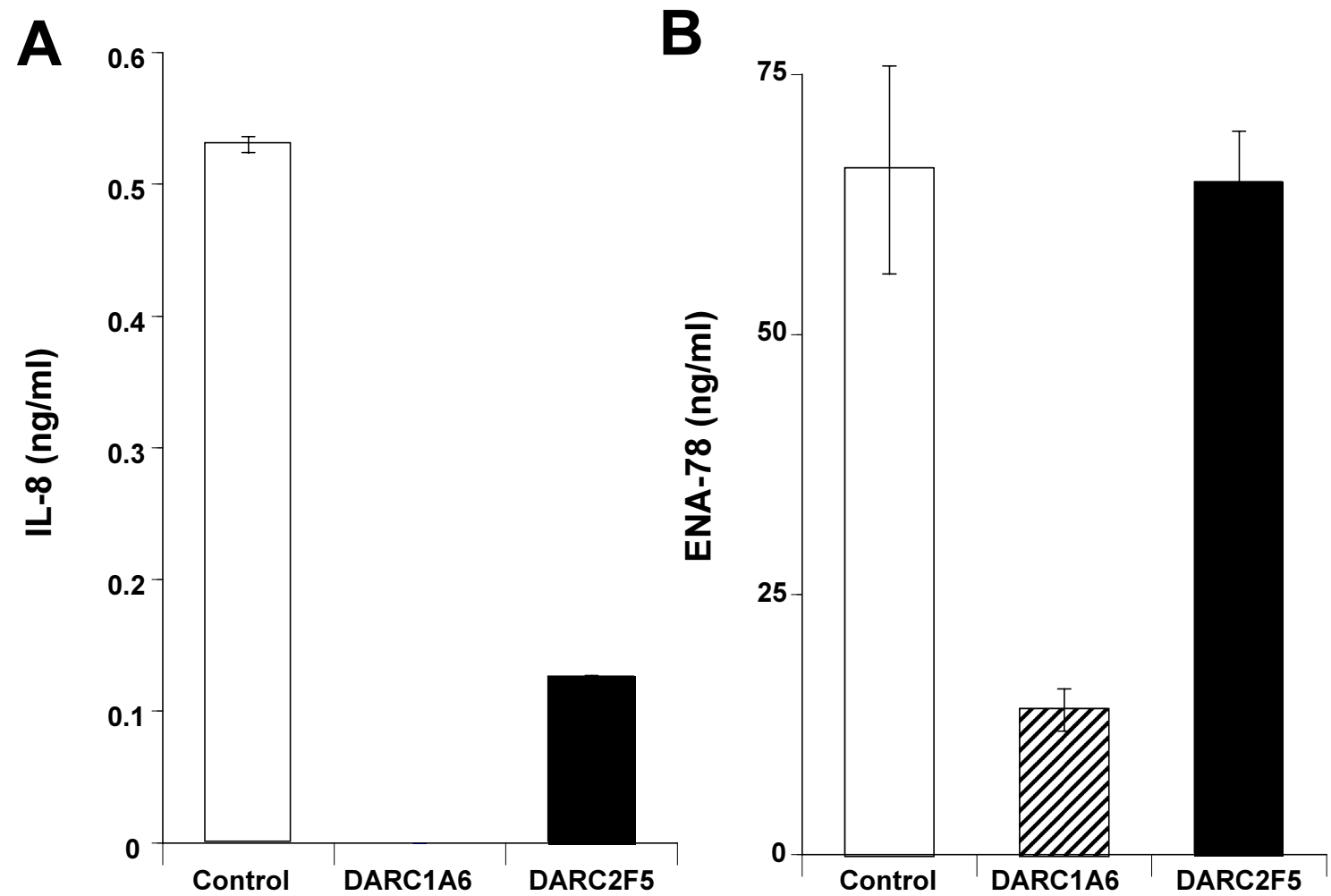

\section{Figure 3}

Comparison of chemokine expression by DARC-A549 cells. The conditioned media from each cell clone was isolated at $72 \mathrm{hr}$ and were compared for A) IL-8, and B) ENA-78 secretion following quantitation by ELISA analysis. All bars represent the mean and standard error of triplicate samples.

following TUNEL staining. We observed no significant differences in the degree of tumor cell apoptosis as detected by this method $(22 \% \pm 2.8 \%$ for DARC1A6, $24 \%$ $\pm 6 \%$ for DARC2F5 and $24 \% \pm 5 \%$ for control). It should be noted however, that these values were determined following analysis of areas containing only viable tumor and therefore do not take into account the increased degree of necrosis associated with the DARC-A549 tumors.

\section{Expression of DARC in A549 tumors results in sequestering} of IL-8 within the tumors

We hypothesized that expression of DARC by the tumor cells themselves would result in the local sequestration of ELR+ CXC chemokines thus preventing the formation of a chemotactic gradient by these molecules and hence the inability to induce productive angiogenic responses. To examine this possibility, tumor sections were examined for the presence of IL-8 by immunohistochemical detection. We detected increased amounts of IL- 8 in the regions of viable tumor cells in tumors derived from DARC1A6 (Fig. 8D) and DARC2F5 (Fig. 8F) cell lines as compared to tumors derived from control cells (Fig. 8B). The staining for IL- 8 was specific as a similar staining pattern was not observed when control pre-immune serum was used as the primary antibody (Fig. $8 \mathrm{~A}, 8 \mathrm{C}$ and $8 \mathrm{E}$ for control, DARC1A6 and DARC2F5 respectively). The IL-8 appeared to be presently mostly within tumor cells and supports the data generated previously following analysis 


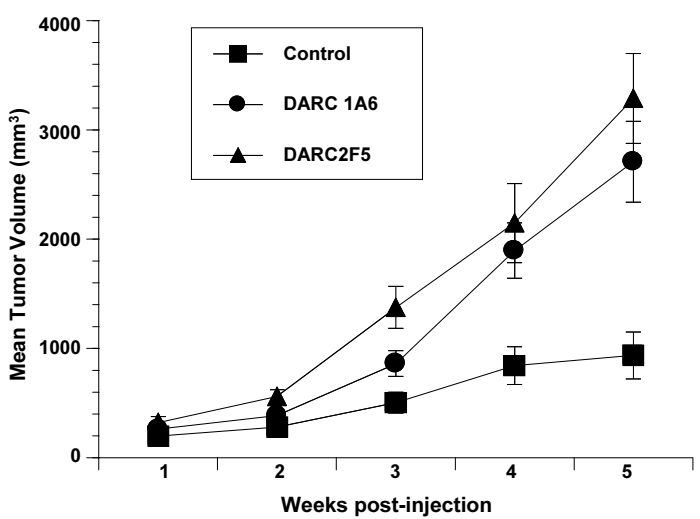

\section{Figure 4}

DARC-A549 cells show enhanced tumor growth in vivo. The growth of DARC-transfected A549 cells was compared in vivo in a SCID mouse model. Tumors were measured externally in three dimensions. Each point is a representation of the mean and standard error for the tumor volume of 10 tumors. At week 7, the DARC-A549 tumors were found to be statistically significantly larger as compared to the control A549 tumors $(p \leq 0.0005)$. of the cell clones in vitro, and suggesting that reduced levels of the ELR+ CXC chemokines are secreted by DARCtransfected tumor cells. As mentioned this may be as a result of the chemokines being bound by DARC within tumor cells likely as a result of binding within the endoplasmic reticulum or golgi apparatus during production and transport to the membrane of these proteins, or alternatively as a result of binding DARC at the surface of cells in a paracrine or autocrine manner and subsequent internalization of the DARC-ligand complex as has been previously observed [10].

DARC-A549 tumors have reduced neovascularization and immune cell infiltration

The degree of neovascularization in DARC-A549 derived tumors was determined following detection of mouseCD31 positive cells by FACS analysis of single cell tumor suspensions generated from $6 \mathrm{~mm}$ biopsy punches of each tumor. We observed a statistically significant decrease in the number of CD31 positive endothelial cells in tumors derived from both DARC1A6 and DARC2F5, as compared to control tumors (Fig. 9, $\mathrm{p}=0.0065$ for DARC1A6 compared to control tumors and $\mathrm{p}=0.0071$ for DARC2F5 compared to control tumors). These data indicated that expression of DARC by A549 tumor cells

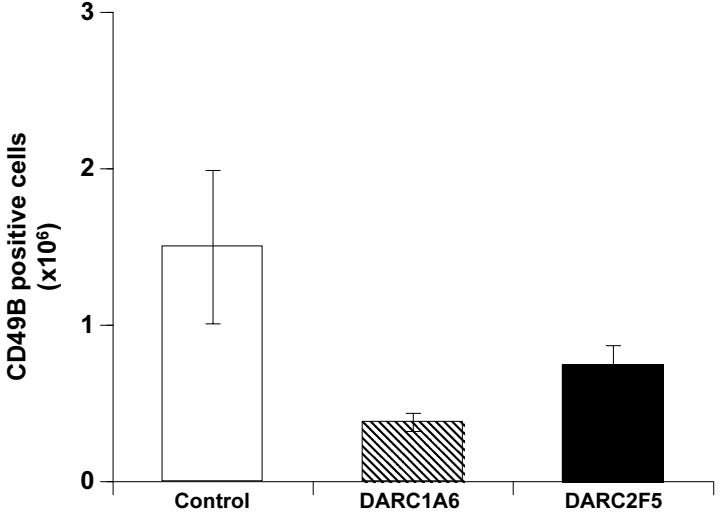

\section{Figure 5}

DARC-A549 derived tumors have reduced tumor cellularity. We assessed the percentage of A549 cells present in each tumor following FACS analysis for human CD49b. We observed a decrease in the percentage of viable cells that were positive for CD49b staining. Each bar is a representation of the mean and standard error for the percent CD49b positive in 5 different tumors for each group. The unpaired ttest $p$-values for DARCIA6 compared to Control tumors is 0.079 and for DARC2F5 compared to Control tumors is 0.13 .

resulted in a decrease in tumor-associated neovascularization concomitant with an increase in tumor necrosis.

In parallel experiments, single cell tumor suspensions were analyzed for the presence of neutrophils, macrophages and NK cells by FACS analysis. Interestingly, we observed statistically significant decreases in the number of neutrophils present in tumors that expressed DARC as compared to control tumors [5.5 $\pm 0.6 \times 10^{5}$ for control tumors as compared to $2.0 \pm 0.4 \times 10^{5}$ for DARC1A6 tumors $(\mathrm{p}=0.0017)$ and as compared to $2.5 \pm$ $0.5 \times 10^{5}$ for DARC2F5 tumors $\left.(\mathrm{p}=0.0064)\right]$. We observed similar significant decreases in the number of NK cells present within DARC tumors as compared to control tumors $\left[7.1 \pm 0.4 \times 10^{5}\right.$ for control tumors as compared to $2.5 \pm 0.6 \times 10^{5}$ for DARC1A6 $(\mathrm{p}=0.0002)$ and as compared to $3.3 \pm 0.6 \times 10^{5}$ for DARC2F5 $\left.(\mathrm{p}=0.0009)\right]$. Although not statistically significant, a decrease was also observed in the number of macrophages found within DARC tumors as compared to control tumors $[5.7 \pm 0.2 \times$ $10^{5}$ for control tumors as compared to $3.4 \pm 0.1 \times 10^{5}$ for DARC1A6 ( $\mathrm{p}=0.32)$ and as compared to $2.8 \pm 0.1 \times 10^{5}$ for DARC2F5 tumors $(p=0.25)$. Taken together these data indicate an interference in the chemotactic gradients 


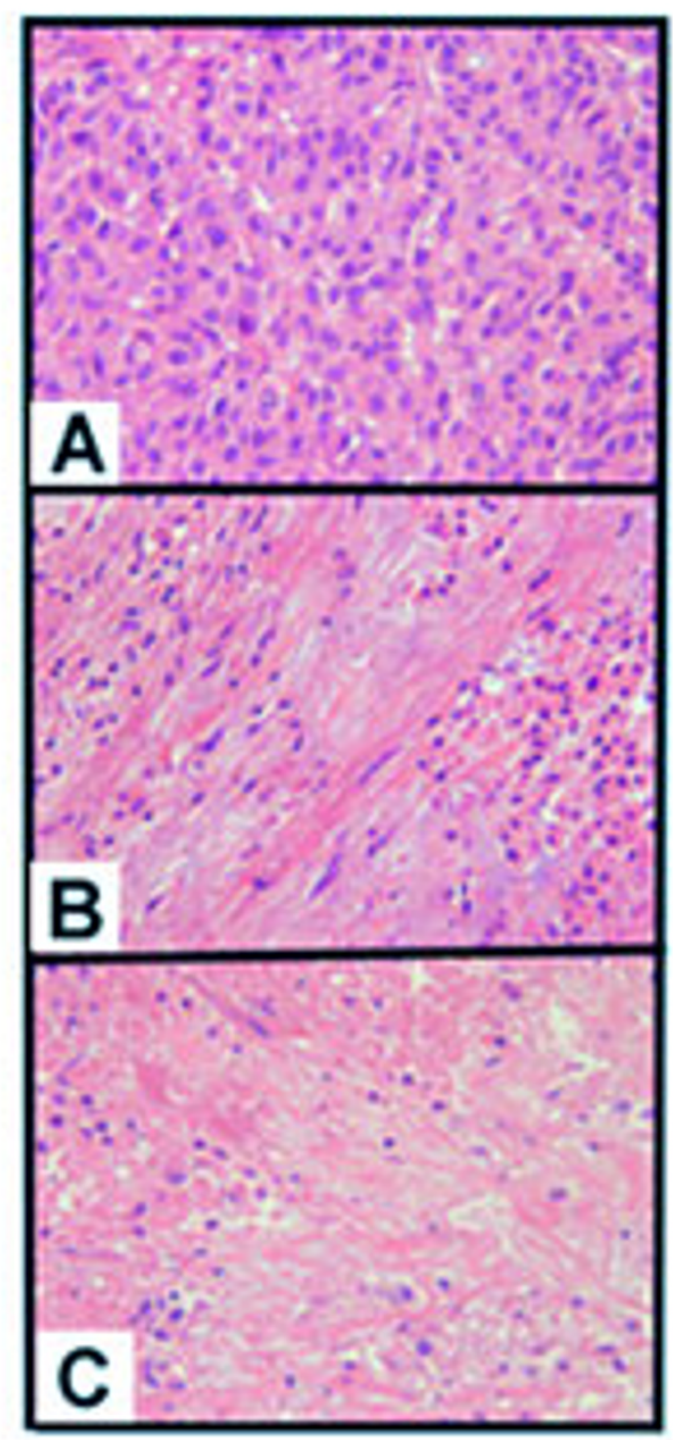

\section{Figure 6}

DARC-A549 Derived tumors have significantly more necrosis than control A549 derived tumors. Hematoxylin and eosin stained tumor sections from Control transfected A549 cells (A) appear very organized and viable. In contrast sections from DARCIA6 (B) and DARC2F5 (C) derived tumors appear to have areas of significant necrosis and cell destruction. Fewer organized areas of viable cells are seen.

required for the recruitment of immune cells into tissue and further support the notion that expression of DARC by tumor cells results in sequestration of chemokines and modulation of chemokine responses in vivo.

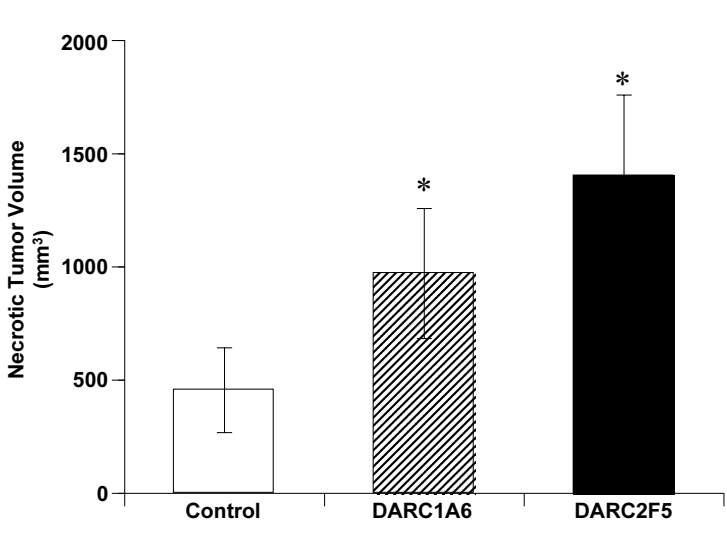

\section{Figure 7}

DARC-A549 Derived tumors have significantly more tumor associated necrosis as compared to control tumors. Each bar represents the mean and standard error of the following sample sizes: Control $n=47$, DARCIA6 $n=100$, DARC2F5 $n=100$. The $p$-value for DARCIA6 compared to Control tumors is $p=0.0007$ and the $p$-value for DARC2F5 compared to Control tumors is $p<0.000 \mathrm{I}$.

\section{DARC-A549 cells have reduced metastatic capacity}

In the human NSCLC/SCID mouse model used in these studies, we have previously found that the A549 cells will spontaneously metastasize to the lungs beginning approximately 4 weeks post-injection of tumor cells subcutaneously $[17,20]$. Moreover, the magnitude of metastasis of this tumor cell line has been shown to directly correlate with the size of the primary tumor $[17,18,20,21]$. To determine whether the effect of increased necrosis and decreased primary tumor vascularity was associated with metastatic potential, we next looked at the metastatic potential of DARC2F5 as compared to control tumors. We analyzed serial sections of paraffin-embedded lung tissue from animals that had received either control vector transfected tumor cells or DARC2F5 tumor cells for the number and size of metastases to the lung at 7 weeks post-injection. We observed a decrease in the number of lung metastases in mice receiving DARC2F5 cells (Fig. 10A), and a statistically significant decrease in the size of these metastases as compared to animals that received control transfected A549 cells (Fig. 10B, p < 0.0001). These data suggest that DARC may interfere with tumor cell escape into the vasculature, possibly as a result of reduced primary tumor neovascularization. Furthermore, DARC expression may inhibit the establishment and growth of micrometastases, again as a 

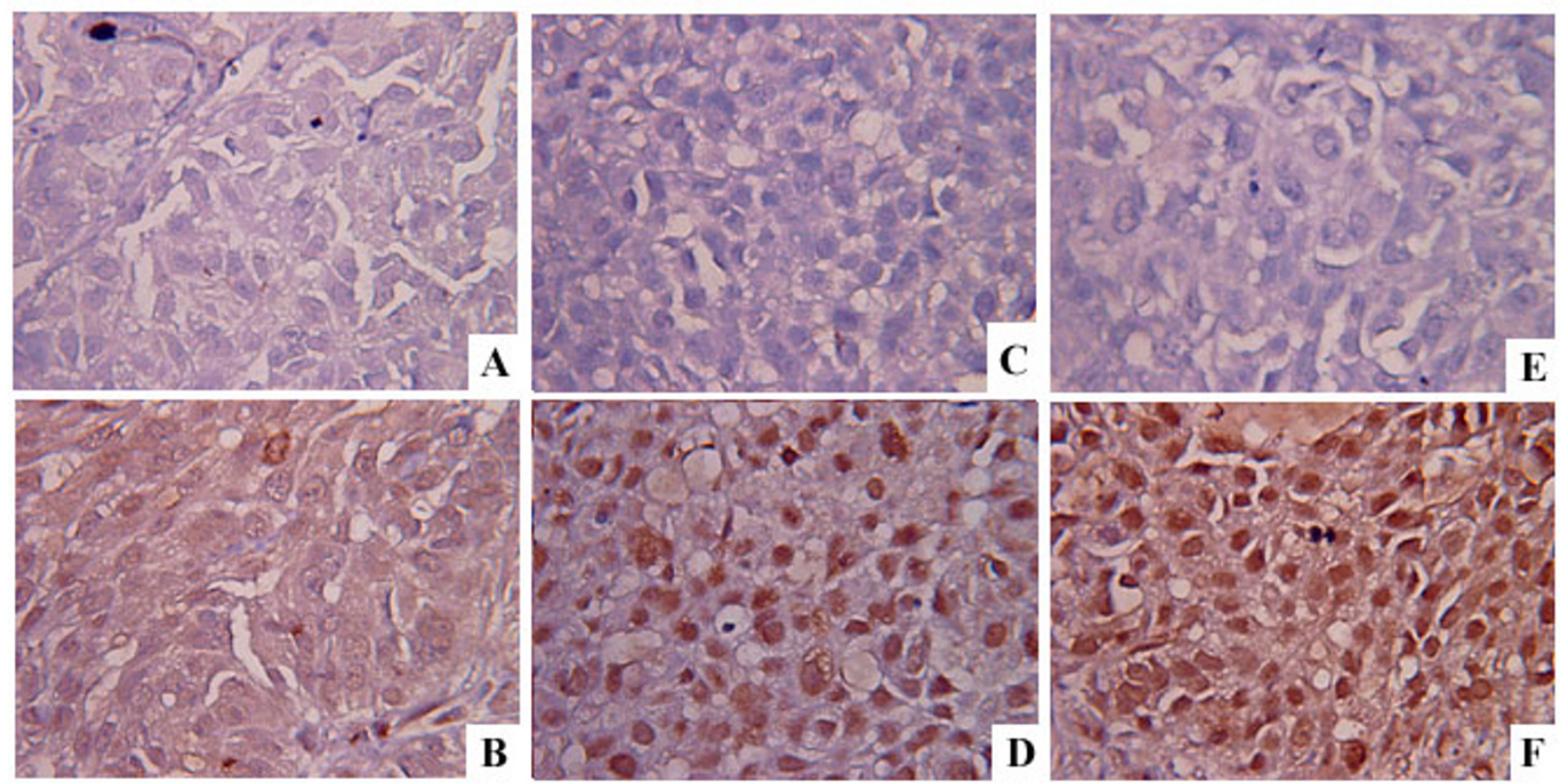

Figure 8

DARC-A549 tumors have increased binding of IL-8 by tumor cells. Control (A\&B), DARCIA6 (C\&D) and DARC2F5 (E\&F) tumors were stained for the presence of IL-8 by immunohistochemical means using rabbit anti-human IL-8 polyclonal serum (B, $D \& F)$. Pre-immune rabbit serum was used as a negative control (A, C\&E).

result of impaired neovascularization responses as a result of inhibition of angiogenic ELR+ CXC chemokine activity.

\section{Discussion}

In this study, we sought to take advantage of the fact that the Duffy antigen receptor for chemokines binds multiple members of the ELR+ CXC family of chemokines that induce angiogenesis in vivo. The importance of these molecules in tumor-associated neovascularization has been previously shown in NSCLC, prostate carcinoma, melanoma, bladder cancer, ovarian and gastric carcinomas $[17,19,20,22-26]$. As DARC has not been shown to be associated with the induction of signal transduction events following ligand binding, we hypothesized that the expression of DARC within the local tumor microenvironment would lead to sequestering of angiogenic CXC chemokines, and thus compete for their binding to signalinducing chemokine receptors on endothelial cells. We generated human NSCLC A549 cells that stably expressed human DARC, and assessed their ability to form tumors in SCID mice. Unexpectedly, we observed that the tumors derived from DARC-expressing A549 cells had an increased tumor volume as compared to control tumors. This increased tumor volume observed in vivo however, was not associated with an enhanced ability to induce neovascularization, as tumors derived from DARCexpressing A549 cells showed increased necrosis and a reduced degree of neovascularization as compared to control tumors. It is also unlikely that DARC-A549 cells expressed increased levels of CXC chemokines in vivo, as ELISAs for IL-8, ENA-78 or GRO- $\alpha$ from tumor homogenates at 7 weeks post-injection showed no significant differences in these protein levels between any of the tumors examined (data not shown). Taken together, these results indicate that overexpression of DARC in the tumor microenvironment likely sequesters ELR+ CXC chemokines within cells thus interfering with the normal chemotactic gradients that need to be formed and thus having profound effects on tumor growth, neovascularization and metastatic potential.

Our results support the hypothesis that DARC functions as a "sink" in vivo, whereby it binds ELR+ CXC chemokines and prevents them from associating with other receptors that would lead to the induction of biological responses, such as angiogenesis. Normally, chemokines form a concentration gradient via a combination of soluble and extracellular matrix bound protein that results in activation and chemotaxis of endothelial and immune cells along that gradient. We observed no differences in 


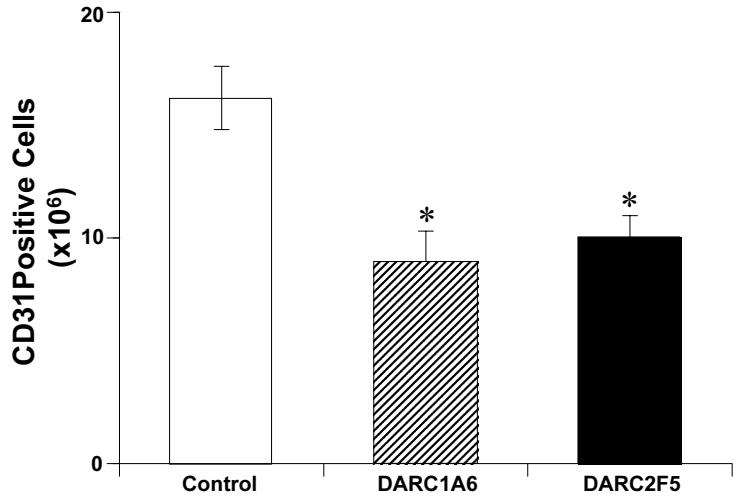

\section{Figure 9}

DARC-A549 tumors have reduced vascularity compared to control A549 tumors. We assessed the degree of vascularization of DARC-derived tumors by FACS analysis for murine CD3I as a marker of endogenous endothelial cells. For all samples, immunological cell types were gated out of the analysis by CD45 staining. Each bar is a representation of the mean and standard error following analysis of the percentage CD3I positive cells from 5 individual tumors for each group. The unpaired t-test $p$-values for DARCIA6 compared to Control tumors is $p=0.0065$ and for DARC2F5 compared to Control tumors the $p$-value is $p=0.007 \mathrm{I}$.

the amounts of ELR+ CXC chemokines found in tumors in vivo suggesting that DARC-expressing and control transfected A549 cells made similar amounts of these proteins, however we did observed decreased amounts of these chemokines in conditioned cell supernatants in vitro. This contrast is likely a reflection of the manner in which the experiments were performed as ELISA analysis of the levels of chemokines in vivo tumors was derived from frozen-thawed homogenates of tumor biopsies and thus the chemokines that would be bound to the surface or trapped within the golgi or endoplasmic reticulum of tumor cells would be free to be measured. In contrast, the ELISA data generated from DARC or control transfected tumor cells in vitro was derived on conditioned cell supernatants only, thus would not measure the amount of chemokine bound to the surface of cells nor sequestered within cells due to inhibition of processing and secretion through the endoplasmic reticulum and golgi apparatus following binding to DARC in DARC-expressing cells. Moreover, our immunohistochemical data from tumor sections suggests increased amounts of IL-8 on or in tumor cells expressing DARC as compared to control tumors in vivo and supports the notion that perhaps the chemotactic gradients of chemokines required to induce appropriate neovascular responses are not formed and instead the chemokines are sequestered by the tumor cells themselves. We cannot however exclude the possibility that DARC may mediate an as yet uncharacterized signal transduction event. DARC is known to lack the highly conserved DRY amino acid motif that interacts with Gproteins in its second intracellular loop [12], however it remains possible that DARC may interact with other cellular receptors or membrane components and elicit specific responses to ligand binding and thus may be contributing to the phenotype we observed via this mechanism.

Although DARC can be detected on a variety of different cell types, including epithelial cells, expression of DARC in vivo is primarily localized to endothelial cells in a variety of organs and tissues. The fact that DARC is expressed on the endothelial cell surface in people who are negative for DARC expression on their erythrocytes [10] implies that DARC plays an important role in modulating endothelial cell biology. It is of interest to note that the pattern of endothelial cells that express high levels of DARC is similar to areas that are key in leukocyte trafficking and extravasation [27-29]. This observation suggests that DARC may be involved in the maintenance of chemotactic gradients across the endothelium. As mentioned our data supports the notion that expression of DARC in the tumor microenvironment sequesters chemokines thus preventing the formation of the appropriate gradients to which various cell types would migrate toward. Indeed our results suggest that DARC-expressing tumors have an impaired ability for NK and neutrophil extravasation into the tumors. DARC is also strongly expressed on post-capillary venules [1], the same cell type that is primarily involved in the initiation of neovascular responses. More recently it has been demonstrated that transgenic mice expressing DARC under an endothelial specific promoter have reduced angiogenic responses in the corneal micropocket assay in response to MIP-2 a CC chemokine that is also known to bind DARC [30]. Thus DARC may play a significant role in the modulation of neovascular responses, and our data would support the idea that DARC plays a significant role in tumor-associated angiogenesis.

We observed an increase in tumor necrosis and a significant decrease in tumor-associated angiogenesis in tumors expressing DARC which may be attributed to DARC acting as a "sink" in vivo and disrupting chemotactic gradients that would be required for angiogenesis to occur. More recently it has been demonstrated that DARC knockout mice undergo modified infiltration of leukocytes in response to inflammatory stimuli such as lipopolysaccharide suggesting that DARC may play a significant role in 

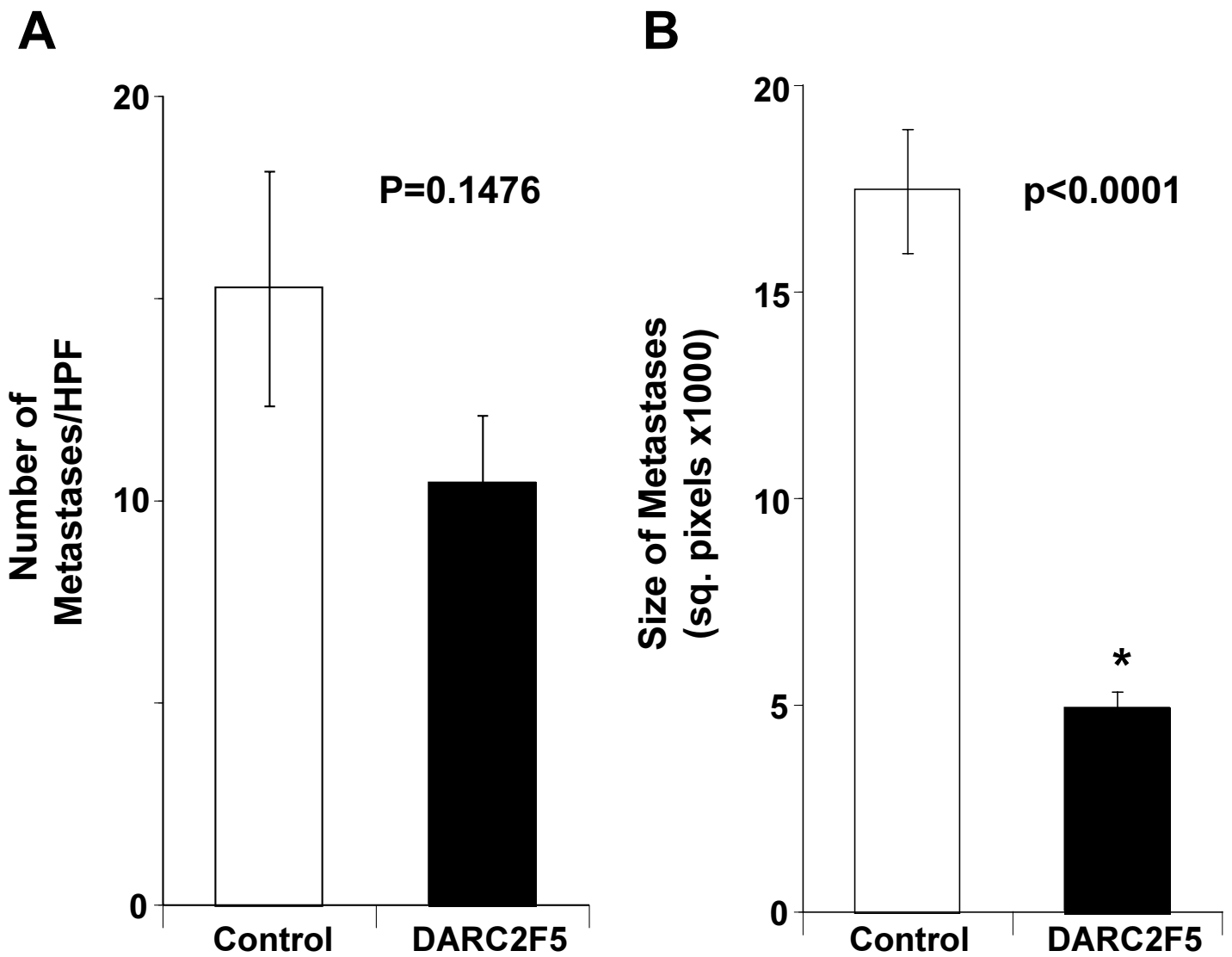

\section{Figure 10}

DARC2F5 cells have impaired metastatic capabilities. The lungs from 5 tumor-bearing mice from each group were sectioned in their entirety. A) The number of metastatic lesions was counted in 7 different sections a minimum of $60 \mu \mathrm{m}$ apart for each lung (40x magnification). Each bar represents the mean and standard error of 35 counts for each group. The $p$-value is 0.1476 . B) The size of each metastatic lesion was determined by morphometric analysis using NIH image analysis software (400x magnification). Each bar represents the mean and standard deviation. For Control $n=534$, and for DARC2F5 $n=36 \mathrm{I}$. The $p-v a l u e$ is $\mathrm{p}<0.0001$.

leukocyte-endothelial cell adhesion and migration $[31,32]$. Moreover, immobilization of IL- 8 is required for neutrophil emigration into tissue and it has been suggested that this occurs via a cooperative mechanism involving IL-8 binding to DARC and heparan sulfate [33]. Thus the decreases in immunological cell types present in DARC tumors also supports the disruption of appropriate chemotactic gradients along the endothelial surface as DARC expressed on tumor cells would act as a "sink" and sequester chemotactic chemokines within the tumor itself. This may partially explain the increase in size of
DARC expressing tumors as normally dying tumor cells in necrotic areas would be removed by infiltrating immune cells leading to resolution of the necrosis and this process might not occur if these cells cannot extravasate into the tumor space, leading to increases in the necrotic areas and hence overall size of the tumor. Impaired infiltration of immune cells might also contribute to the reduced neovascularization observed in DARC-expressing tumors as it has been shown that the presence of macrophages may contribute to tumor growth and progression and induction of tumor neovascularization [34,35]. As we observed 
a slight reduction in the number of tumor-associated macrophages in DARC-A549 tumors as compared to control tumors it remains possible that in addition to DARC directly binding angiogenic chemokines and preventing them from directly affecting the neovasculature, that reduction in infiltrating immune cells may also contribute to the reduced neovascularization associated with DARCA549 tumor growth.

As mentioned, we hypothesized that DARC expression by the tumor cells would bind the angiogenic chemokines and sequester them from endothelial cells, thus preventing endothelial cell chemotaxis and tumor-associated angiogenesis. The lack of tumor-associated angiogenic activity would lead to significant increases in tumor necrosis, which is what was observed in our DARC-A549 generated tumors. The lack of endothelial cell recruitment into the tumor may partly explain why we observed a reduction in the spontaneous metastasis of the DARCA549 tumors, since metastasis is thought to occur by tumor cell invasion of the vasculature. The ability of DARC to inhibit neovascular responses could result in the inhibition of the establishment and growth of micrometastases. This hypothesis is supported by our data that DARC2F5 cells have fewer and significantly smaller metastatic nodules in the lung, as compared to the control A549 cells.

\section{Conclusions}

In summary, we have shown that expression of DARC in the tumor microenvironment results in altered tumor growth associated with a reduction in neovascularization and an increase in tumor necrosis. While the mechanism behind this altered phenotype is as yet unclear it appears that expression of DARC by the tumor cells alters the tumor-endothelial cell relationship, perhaps by sequestering angiogenic factors and acting as a chemokine sink as has been previously suggested. Thus expression of DARC by human tumors may be correlated with a less aggressive and metastatic phenotype in vivo. Our results clearly indicate the important role of DARC in endothelial cell biology and support the need for further study of the function of this receptor in various cell types.

\section{Materials and methods \\ Reagents}

Polyclonal rabbit anti-human IL-8 sera was produced by immunization of rabbits with IL-8, (Peprotech, Rocky Hill, NJ) in multiple intradermal sites with complete Freund's adjuvant. This antibody has been previously well characterized for its neutralizing capacity [17]. The IL-8 anti-serum specificity has been confirmed by Western blot analysis against recombinant human IL- 8 and was found to neutralize $30 \mathrm{ng}$ of IL-8 at a dilution of 1:1000 [17]. Furthermore, in a sandwich ELISA, this antibody is specific for IL-8 without cross-reactivity to a panel of 12 other recombinant human cytokines or the murine chemokines KC and MIP-2 [17].

\section{Human cell lines}

The A549 human adenocarcinoma cell line (ATCC CCL 185) was purchased from the American Type Culture Collection (Rockville MD). A549 cells were maintained in RPMI 1640 medium supplemented with $1 \mathrm{mM}$ glutamine, $25 \mathrm{mM}$ Hepes buffer, $100 \mathrm{U} / \mathrm{ml}$ penicillin, 100 $\mathrm{ng} / \mathrm{ml}$ streptomycin and 10\% fetal bovine serum (all from Whitaker Biomedical Products, Whitaker CA).

\section{Generation of stably transfected NSCLC cell lines}

The cDNA for human DARC was amplified by RT-PCR from total RNA isolated from K562-DARC cells that had been stably transfected to express DARC using the following primer pair: Forward - 5' CAT CTG AAT TCC TGC AGA GAC CTT GTT C 3' and Reverse - 5' AAA GGA TCC GTC TAG ACT TTA ATT CAG GTT CAG 3'. RT-PCR was performed using the Access RT-PCR kit according to the manufacturer's directions (Promega Corp., Madison WI). The reverse transcriptase reaction was performed at $48^{\circ} \mathrm{C}$ for $45 \mathrm{~min}$, followed by denaturation at $94^{\circ} \mathrm{C}$ for $2 \mathrm{~min}$. PCR amplification was then performed using the following cycle conditions: $94^{\circ} \mathrm{C}$ for $1 \mathrm{~min}, 56^{\circ} \mathrm{C}$ for $1 \mathrm{~min}$, $68^{\circ} \mathrm{C}$ for $2 \mathrm{~min}$ for a total of 40 cycles, followed by a 7 min extension cycle at $68^{\circ} \mathrm{C}$. The resulting $1.2 \mathrm{~kb}$ DNA band was gel purified using the Wizard PCR purification kit and cloned into the pTARGET mammalian expression plasmid system (both from Promega Corp., Madison WI). A549 cells were transfected with varying quantities of plasmid DNA using the calcium phosphate-mediated transfection technique [36]. Following transfection, cells were grown in the presence of $400 \mu \mathrm{g} / \mathrm{ml}$ of $\mathrm{G} 418$ (Geneticin, Gibco BRL, Grand Island, NY), and G418 resistant colonies were isolated and expanded in culture. One empty pTARGET control vector transfected line was chosen for further comparisons and from herein will be referred to as "control". Two independently generated DARC-expressing A549 cell lines were chosen for further analysis, DARC1A6 and DARC2F5.

\section{ELISA analysis}

The quantity of IL-8, ENA-78, and GRO- $\alpha$, GRO- $\gamma$, IP-10 and MIG present in conditioned cell supernatants was determined by specific ELISA, using a modification of the double ligand method as previously described $[13,37]$. Briefly, flat-bottomed 96-well microtiter plates were coated with $50 \mu \mathrm{l} /$ well of specific polyclonal rabbit antiCXC chemokine antibodies $(1 \mu \mathrm{g} / \mathrm{ml}$ in $0.6 \mathrm{M} \mathrm{NaCl}, 0.26$ $\left.\mathrm{M} \mathrm{H}_{3} \mathrm{BO}_{3}, 0.08 \mathrm{~N} \mathrm{NaOH}, \mathrm{pH} 9.6\right)$ for $24 \mathrm{hr}$ at $4^{\circ} \mathrm{C}$, and then washed with PBS pH 7.5 plus $0.05 \%$ Tween-20 (wash buffer). Plates were blocked with 2\% BSA in PBS for $1 \mathrm{~h}$ at $37^{\circ} \mathrm{C}$ and then washed three times with wash 
buffer. $50 \mu \mathrm{l}$ of sample (1:10 and neat) was added and the plates were incubated at $37^{\circ} \mathrm{C}$ for $1 \mathrm{~h}$. Plates were washed three times, $50 \mu \mathrm{l}$ of appropriate biotinylated polyclonal anti-CXC chemokine antibodies $(3.5 \mathrm{ng} / \mu \mathrm{l}$ in PBS, $\mathrm{pH}$ $7.5,0.05 \%$ Tween- 20 and $2 \%$ FBS) were added, and plates were incubated at $37^{\circ} \mathrm{C}$ for $45 \mathrm{~min}$. Plates were washed three times, streptavidin-peroxidase conjugate was added, and the plates were incubated for $30 \mathrm{~min}$ at $37^{\circ} \mathrm{C}$. Plates were washed again and $100 \mu \mathrm{l}$ of 3, 3', 5, 5'-tetramethylbenzidine (TMB) chromogenic substrate was added. Plates were incubated at room temperature to the desired extinction and the reactions were terminated by the addition of $100 \mu \mathrm{l} /$ well of $1 \mathrm{M} \mathrm{H}_{3} \mathrm{PO}_{4}$. Plates were read at 450 $\mathrm{nm}$ in an automated microtiter plate reader and the amount of CXC chemokine present was determined by interpolation of a standard curve generated by known amounts of recombinant CXC chemokine protein. The sensitivity for the specific chemokine ELISAs was $>50 \mathrm{pg} /$ $\mathrm{ml}$ and these assays failed to cross-react with a panel of other known cytokines and chemokines.

\section{Northern blot analysis}

Expression of DARC was detected at the message level by Northern blot analysis. Total RNA was extracted from cells in Trizol (Gibco BRL, Rockville MD), and $10 \mu \mathrm{g}$ of RNA was subjected to formaldehyde agarose gel electrophoresis. The RNA was then transferred overnight by capillary transfer in $10 \times$ SSC to nylon membranes (Roche, Indianapolis IN) and the membranes were subsequently UV cross-linked. For mRNA detection of the northern blot, dioxygenin (DIG)-labeled probes were generated following random priming reactions of a gel purified cDNA fragment using the DIG-High Prime kit according to the manufacturer's recommendations (Roche, Indianapolis IN). Hybridization and detection of the DIG-labeled probes was performed according to the manufacturer's directions (Roche, Indianapolis IN). Ethidium bromide staining of the blot for $28 \mathrm{~S}$ and $18 \mathrm{~S}$ rRNA was used as a control to ensure equal loading of the gel.

\section{Detection of DARC on transfected cells}

DARC protein was detected on transfected cells by FACS analysis. Briefly, cells were removed from flasks in $1 \mathrm{mM}$ ice cold EDTA in PBS and then incubated at $4{ }^{\circ} \mathrm{C}$ for $1 \mathrm{hr}$ with $5 \mu \mathrm{g} / \mathrm{ml} \mathrm{Fy} 6$ monoclonal antibody to human DARC or with isotype control antibody. Following two washes with ice-cold PBS containing $0.2 \%$ FBS, cells were incubated with FITC-conjugated anti-mouse antibody and incubated for an additional $1 \mathrm{hr}$ at $4{ }^{\circ} \mathrm{C}$. Cells were again washed two times, and were then fixed with $2 \%$ paraformaldehyde prior to FACS analysis.

\section{Binding of IL-8 by DARC transfected cells}

Transfected cells were removed from flasks following incubation in $1 \mathrm{mM}$ ice cold EDTA in PBS. Cells were then incubated in the presence of biotinylated IL-8, and bound ligand was detected using FITC-conjugated streptavidin according to the manufacturer's protocol (Pharmingen, San Diego CA). Bound IL-8 ligand was then detected by FACS analysis.

\section{Human NSCLC-SCID mouse chimeras}

Six to eight week old CB-17 SCID mice were injected subcutaneously (sc) in each flank with $1 \times 10^{6}$ A549 NSCLC cells in $100 \mu \mathrm{l}$. On a weekly basis once palpable tumors were visible, tumors were measured in three dimensions with engineer's calipers. Tumor volume was calculated using the equation axbxc where ' $a$ ' is the longest diameter, ' $\mathrm{b}$ ' is its perpendicular, and ' $\mathrm{c}$ ' is the depth of the tumor. At 3, 4 and 7 weeks post-tumor cell injection, animals were euthanized by ketamine overdose, the tumors were removed and measured as described above, and a portion was fixed in $4 \%$ paraformaldehyde for histological analyses. Another portion of the tumor was snap frozen and stored at $-70^{\circ} \mathrm{C}$ for generation of protein extracts. Total protein extracts were generated by subsequent homogenization and sonication in Complete ${ }^{\mathrm{TM}}$ antiprotease buffer (Roche Molecular Diagnostics, Indianapolis, IN) and filtration through a $1.2 \mu \mathrm{m}$ filter. Protein concentration was determined using the BCA Protein Assay Kit (Pierce, Rockford IL), and specific chemokine ELISAs were performed as described above. All chemokine concentrations were normalized to total protein.

\section{FACS analysis}

Two $6 \mathrm{~mm}$ tumor punches were minced in $5 \mathrm{ml}$ of Dispase $^{\circledast}$ (Becton Dickinson, San Jose, CA) solution and incubated with agitation for $1 \mathrm{~h}$ in a $37^{\circ} \mathrm{C}$ water bath. Cells were further separated by repeatedly aspirating the cell suspension through a $20 \mathrm{ml}$ syringe, and filtration through gauze. Cells were then pelleted at $600 \times \mathrm{g}$ for 10 min, resuspended in sterile water for $30 \mathrm{~s}$ to lyse remaining red blood cells, and washed in $1 \times$ PBS. Cells were counted and transferred at a concentration of $5 \times 10^{6}$ cells/ml to fluorescent antibody solution (1\% FA buffer, $1 \%$ FBS, and $0.1 \%$ sodium azide), and maintained at $4{ }^{\circ} \mathrm{C}$ for the remainder of the staining procedure. $100 \mu \mathrm{l}$ of the cell suspension was labeled with FITC-conjugated antimouse CD31 to detect mouse endothelial cells, or with PE-conjugated anti-human CD49b to detect human A549 tumor cells (both from Pharmingen, San Diego CA). All samples were simultaneously incubated with Tri-colorconjugated anti-mouse CD45 to detect endogenous immunological cell types that were then gated out. These results are therefore presented as the percentage of positive cells following the exclusion of murine CD45 positive cell populations. Immune cells were also detected in parallel samples using PE-conjugated anti-mouse DX5 (for NK cells, Pharmingen, San Diego CA), FITC-conjugated Ly-6G (for neutrophils, Pharmingen, San Diego 
CA), and FITC-conjugated Moma-2 (for macrophages, Serotec, Raleigh NC). The unbound antibody was washed with FA buffer and the cell suspension subsequently analyzed by FACS.

\section{In situ detection of apoptotic tumor cells}

For each tumor group, three paraffin-embedded tumor sections were taken a minimum of $60 \mu \mathrm{m}$ apart from 5 different tumors ( $\mathrm{n}=15$ per group). For detection of apoptosis, DNA fragmentation was determined using the In situ cell death detection kit (Roche, Indianapolis IN). The percentage of cells staining positive by TUNEL was determined in 10 random fields of view at $200 \times$ magnification. Fields of view that were completely necrotic were excluded for these purposes.

\section{Immunohistochemical detection of IL-8}

Tumor sections were subjected to immunohistochemical staining for IL-8 as previously described $[17,38]$. Briefly, tumor sections were incubated in a 1:500 dilution of rabbit anti-human IL-8 serum or rabbit pre-immune serum. Primary antibody was detected with biotinylated goat anti-rabbit antibodies followed by incubation with streptavidin-conjugated HRP and colorimetric detection with 3,3'-diaminobenzidine (DAB) (all detection reagents from Vector Laboratories, Burlingame CA). Sections were counterstained in Mayer's hematoxylin.

\section{Statistical and morphometric analyses}

All statistical analysis of data was performed using the Statview 4.5 software program (SAS Institute Inc., Cary NC). Groups of data that appeared statistically different were compared by Students $t$ test for comparison of means, and were considered statistically significant if $\mathrm{p}$ values of $<0.05$ were obtained. The Mann-Whitney U test was used to compare groups of observations that did not appear normally distributed, and were considered statistically significant if p-values of $<0.05$ were obtained. For analysis of lung metastases and necrotic areas, morphometric analysis was performed on at least 16 separate hematoxylin and eosin stained sections taken $60 \mu \mathrm{m}$ apart from each of 5 different animals under $200 \times$ magnification. An Olympus BH-2 microscope coupled to a Sony 3CCD camera was used to capture images that were then analyzed for total area of metastatic lesions using the NIH Image 1.55 software. For determination of tumor necrosis, the average percentage of necrotic area per high power field $(200 \times)$ for each tumor was determined by morphometric analysis, and this number was then multiplied by the tumor volume yielding the average necrotic volume for each tumor.

\section{Author's contributions}

CLA performed all molecular and in vitro cellular assays, cell line characterization, in vivo animal model work and subsequent analysis of tumors by FACS, immunohistochemistry and morphometric analysis in addition to writing this manuscript. JAB assisted with the animal experimentation and ELISA analyses. MDB performed the IL-8 immunohistochemistry and TUNEL analyses and assisted in the animal experimentation and ELISA analyses. RMS conceived and directed the study and assisted with preparation of the final manuscript.

\section{Acknowledgements}

This work has been supported, in part, by grants from the National Institutes of Health (CA87879, HL66027, P50HL67665, and P50CA90388 for R.M.S. and KO8HL04493 for J.A.B.). C.L.A. is a research fellow of the National Cancer Institute of Canada supported with funds provided by the Terry Fox Run.

\section{References}

I. Chaudhuri A, Polyakova J, Zbrzezna V, Williams K, Gulati S, Pogo AO: Cloning of glycoprotein D cDNA, which encodes the major subunit of the Duffy blood group system and the receptor for the Plasmodium vivax malaria parasite. Proc Natl Acad Sci U S A 1993, 90:10793-10797.

2. Chaudhuri A, Zbrzezna V, Johnson C, Nichols M, Rubinstein P, Marsh WL, Pogo AO: Purification and characterization of an erythrocyte membrane protein complex carrying Duffy blood group antigenicity. Possible receptor for Plasmodium vivax and Plasmodium knowlesi malaria parasite. J Biol Chem 1989 264:13770-13774.

3. Miller LH, Mason SJ, Dvorak JA, McGinniss MH, Rothman IK: Erythrocyte receptors for (Plasmodium knowlesi) malaria: Duffy blood group determinants. Science 1975, 189:561-563.

4. Horuk R, Chitnis CE, Darbonne WC, Colby TJ, Rybicki A, Hadley T], Miller $\mathrm{LH}$ : A receptor for the malarial parasite Plasmodium vivax: the erythrocyte chemokine receptor. Science 1993, 261: II82-1184.

5. Chaudhuri A, Zbrzezna V, Polyakova J, Pogo AO, Hesselgesser J, Horuk R: Expression of the Duffy antigen in $\mathbf{K 5 6 2}$ cells. Evidence that it is the human erythrocyte chemokine receptor. J Biol Chem 1994, 269:7835-7838.

6. Lu ZH, Wang ZX, Horuk R, Hesselgesser J, Lou YC, Hadley TJ, Peiper SC: The promiscuous chemokine binding profile of the Duffy antigen/receptor for chemokines is primarily localized to sequences in the amino- terminal domain. J Biol Chem 1995, 270:26239-26245.

7. Szabo MC, Soo KS, Zlotnik A, Schall TJ: Chemokine class differences in binding to the Duffy antigen-erythrocyte chemokine receptor. J Biol Chem 1995, 270:25348-2535I.

8. Chaudhuri A, Nielsen S, Elkjaer ML, Zbrzezna V, Fang F, Pogo AO: Detection of Duffy antigen in the plasma membranes and caveolae of vascular endothelial and epithelial cells of nonerythroid organs [see comments]. Blood 1997, 89:70I-7I2.

9. Horuk R, Martin A, Hesselgesser J, Hadley T, Lu ZH, Wang ZX, Peiper SC: The Duffy antigen receptor for chemokines: structural analysis and expression in the brain. J Leukoc Biol 1996, 59:29-38.

10. Peiper SC, Wang ZX, Neote K, Martin AW, Showell HJ, Conklyn MJ, Ogborne K, Hadley T], Lu ZH, Hesselgesser J, et al.: The Duffy antigen/receptor for chemokines (DARC) is expressed in endothelial cells of Duffy negative individuals who lack the erythrocyte receptor. J Exp Med 1995, |8|:|3||-|3|7.

II. Neote K, Mak JY, Kolakowski L. F., Jr., Schall TJ: Functional and biochemical analysis of the cloned Duffy antigen: identity with the red blood cell chemokine receptor. Blood 1994, 84:44-52.

12. Hadley TJ, Peiper SC: From malaria to chemokine receptor: the emerging physiologic role of the Duffy blood group antigen. Blood 1997, 89:3077-309।.

13. Strieter RM, Kunkel SL, Elner VM, Martonyi CL, Koch AE, Polverini PJ, Elner SG: Interleukin-8. A corneal factor that induces neovascularization. Am J Pathol | 992, I 4 I: | 279- | 284. 
14. Koch AE, Polverini PJ, Kunkel SL, Harlow LA, DiPietro LA, Elner VM, Elner SG, Strieter RM: Interleukin-8 as a macrophage-derived mediator of angiogenesis [see comments]. Science 1992 258: $1798-1801$.

I5. Hu DE, Hori Y, Fan TP: Interleukin-8 stimulates angiogenesis in rats. Inflammation 1993, I 7: I35-143.

16. Strieter RM, Polverini PJ, Kunkel SL, Arenberg DA, Burdick MD, Kasper J, Dzuiba J, Van Damme J, Walz A, Marriott D, et al.: The functional role of the ELR motif in CXC chemokine-mediated angiogenesis. J Biol Chem I995, 270:27348-27357.

17. Arenberg DA, Kunkel SL, Polverini PJ, Glass M, Burdick MD, Strieter RM: Inhibition of interleukin-8 reduces tumorigenesis of human non-small cell lung cancer in SCID mice. J Clin Invest 1996, 97:2792-2802

18. Arenberg DA, Keane MP, DiGiovine B, Kunkel SL, Morris SB, Xue YY, Burdick MD, Glass MC, lannettoni MD, Strieter RM: Epithelial-neutrophil activating peptide (ENA-78) is an important angiogenic factor in non-small cell lung cancer. J Clin Invest 1998, 102:465-472.

19. Moore BB, Arenberg DA, Stoy K, Morgan T, Addison CL, Morris SB Glass M, Wilke C, Xue YY, Sitterding S, Kunkel SL, Burdick MD, Strieter RM: Distinct CXC chemokines mediate tumorigenicity of prostate cancer cells. Am J Pathol 1999, I54:I503-I5I 2.

20. Arenberg DA, Polverini PJ, Kunkel SL, Shanafelt A, Hesselgesser J, Horuk R, Strieter RM: The role of CXC chemokines in the regulation of angiogenesis in non- small cell lung cancer. J Leukoc Biol 1997, 62:554-562.

21. Addison CL, Arenberg DA, Morris SB, Xue YY, Burdick MD, Mulligan MS, lannettoni MD, Strieter RM: The CXC chemokine, monokine induced by interferon-gamma, inhibits non- small cell lung carcinoma tumor growth and metastasis. Hum Gene Ther 2000, I I:247-26I.

22. Singh RK, Gutman M, Radinsky R, Bucana CD, Fidler IJ: Expression of interleukin 8 correlates with the metastatic potential of human melanoma cells in nude mice. Cancer Res 1994, 54:3242-3247.

23. Reiland J, Furcht LT, McCarthy JB: CXC-chemokines stimulate invasion and chemotaxis in prostate carcinoma cells through the CXCR2 receptor. Prostate 1999, 41:78-88

24. Xu L, Fidler IJ: Interleukin 8: an autocrine growth factor for human ovarian cancer. Oncol Res 2000, I 2:97-I06.

25. Inoue K, Slaton JW, Kim SJ, Perrotte P, Eve BY, Bar-Eli M, Radinsky R, Dinney CP: Interleukin 8 expression regulates tumorigenicity and metastasis in human bladder cancer. Cancer Res 2000 60:2290-2299.

26. Kitadai Y, Takahashi Y, Haruma K, Naka K, Sumii K, Yokozaki H, Yasu W, Mukaida N, Ohmoto Y, Kajiyama G, Fidler IJ, Tahara E: Transfection of interleukin-8 increases angiogenesis and tumorigenesis of human gastric carcinoma cells in nude mice. $\mathrm{Br} J$ Cancer 1999, 8 1:647-653.

27. Hechtman DH, Cybulsky MI, Fuchs HJ, Baker JB, Gimbrone M. A., Jr.: Intravascular IL-8. Inhibitor of polymorphonuclear leukocyte accumulation at sites of acute inflammation. I Immunol |991, | 47:883-892.

28. Lawrence MB, Springer TA: Leukocytes roll on a selectin at physiologic flow rates: distinction from and prerequisite for adhesion through integrins. Cell 1991, 65:859-873.

29. Rot A: Endothelial cell binding of NAP-I/IL-8: role in neutrophil emigration. Immunol Today 1992, I 3:29|-294.

30. Du J, Luan J, Liu H, Daniel TO, Peiper S, Chen TS, Yu Y, Horton LW, Nanney LB, Strieter RM, Richmond A: Potential role for Duffy antigen chemokine-binding protein in angiogenesis and maintenance of homeostasis in response to stress. J Leukoc Biol 2002, $71:|4|-\mid 53$

31. Dawson TC, Lentsch AB, Wang Z, Cowhig JE, Rot A, Maeda N, Peiper $S C$ : Exaggerated response to endotoxin in mice lacking the Duffy antigen/receptor for chemokines (DARC). Blood 2000 96: $1681-1684$

32. Luo H, Chaudhuri A, Zbrzezna V, He Y, Pogo AO: Deletion of the murine Duffy gene (Dfy) reveals that the Duffy receptor is functionally redundant. Mol Cell Biol 2000, 20:3097-3 IOI.

33. Middleton J, Neil S, Wintle J, Clark-Lewis I, Moore H, Lam C, Auer M, Hub E, Rot A: Transcytosis and surface presentation of IL-8 by venular endothelial cells. Cell 1997, 9 1:385-395.
34. Sunderkotter C, Goebeler M, Schulze-Osthoff K, Bhardwaj R, Sorg C: Macrophage-derived angiogenesis factors. Pharmacol Ther 1991, 5 I: | 95-2 |6.

35. Sunderkotter C, Steinbrink K, Goebeler M, Bhardwaj R, Sorg C: Macrophages and angiogenesis. J Leukoc Biol 1994, 55:410-422.

36. Graham FL, Eb A. J. van der: Transformation of rat cells by DNA of human adenovirus 5. Virology 1973, 54:536-539.

37. Standiford TJ, Kunkel SL, Basha MA, Chensue SW, Lynch J. P., 3rd, Toews GB, Westwick J, Strieter RM: Interleukin-8 gene expression by a pulmonary epithelial cell line. A model for cytokine networks in the lung. J Clin Invest 1990, 86: 1945-1953.

38. Arenberg DA, Kunkel SL, Polverini PJ, Morris SB, Burdick MD, Glass MC, Taub DT, lannettoni MD, Whyte RI, Strieter RM: Interferongamma-inducible protein $I 0$ (IP-IO) is an angiostatic factor that inhibits human non-small cell lung cancer (NSCLC) tumorigenesis and spontaneous metastases. J Exp Med 1996, | 84:98|-992.

\section{Pre-publication history}

The pre-publication history for this paper can be accessed here:

http://www.biomedcentral.com/1471-2407/4/28/prepub 
Publish with Bio Med Central and every scientist can read your work free of charge

"BioMed Central will be the most significant development for disseminating the results of biomedical research in our lifetime. " Sir Paul Nurse, Cancer Research UK

Your research papers will be:

- available free of charge to the entire biomedical community

- peer reviewed and published immediately upon acceptance

- cited in PubMed and archived on PubMed Central

- yours - you keep the copyright 